\title{
Effects of atmospheric oscillations on infectious diseases: the case of Chagas disease in Chile
}

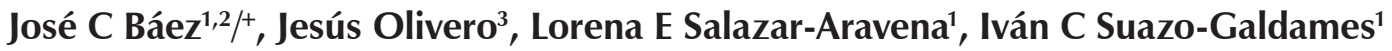 \\ ${ }^{1}$ Universidad Autónoma de Chile, Facultad de Ciencias de la Salud, Instituto de Ciencias Biomédicas, Santiago, Chile \\ ${ }^{2}$ Instituto Español de Oceanografía, Centro Oceanográfico de Málaga, Málaga, Spain \\ ${ }^{3}$ Universidad de Málaga, Facultad de Ciencias, Departamento de Biología Animal, Málaga, Spain
}

BACKGROUND Currently, there is an increasing global interest for the study of how infectious diseases could be linked to climate and weather variability. The Chagas disease was described in 1909 by Carlos Chagas, and is caused by the flagellate protozoan Trypanosoma cruzi. The Chagas disease is considered one of the biggest concerns in public health in Latin America. In Chile, the main vectors involved in the transmission of $T$. cruzi are arthropods of the Triatominae subfamily. Moreover, another main transmission way is through of vectors by fecal-urine way, however, oral way also has been described among others transmission form.

OBJECTIVES In order to get understand outbreaks of Chagas-disease, we search for possible relationships between the frequency of cases in the Chilean population and atmospheric oscillations.

METHODS We explored the two most important atmospheric oscillations in the Southern Hemisphere: southern oscillation index (SOI) and Antarctic oscillation (AAO), during the available years with official data. Because the number of migrant people born outside from Chile increasing significantively between 2014 and 2018, we used for the analysis two different periods from data available official data: (i) 2001 to 2014, (ii) 2001 to 2017.

FINDINGS For both periods we observed a significant and positive relation between AAO one year before. However, for the 2001 to 2014 period positive SOI one year before, which is related with La Niña phases, was the more important variable.

MAIN CONCLUSIONS The Chagas disease frequency per year in Chile was found to depend mainly on SOI in previous year, whose values can be determined one year in advance. Therefore, it is possible to partially forecast annual frequency patterns. This could have important applications in public health strategies and for allocating resources for the management of the disease.

Key words: atmospheric teleconnections - SOI - AAO - temporal predictions

The world is currently experiencing a period of rapid global warming, ${ }_{,}^{(1)}$ primarily driven by human activity. ${ }^{(2)}$ Although there is an increasing concern over the impact of global warming on human health, such as food safety, ${ }^{(3)}$ it is difficult to predict its influence in public health. In this context, climate change is expected to increase the prevalence of a wide range of health risks, mainly those derived from insect transmission such as Malaria, ${ }^{(4,5)}$ and new emergent infections such as Zika fever. For this reason, there is an increasing global interest in the study of infectious diseases and its link with climate variability. ${ }^{(6,7)} \mathrm{A}$ first step in this direction should be to understand whether inter-annual climate oscillations have significant influence on the occurrence of disease outbreaks. However, at present there are scarce studies linking atmospheric oscillations with seasonality and frequency of infectious diseases affecting humans. ${ }^{(8,9)}$

doi: 10.1590/0074-02760180569

Financial support: This study was supported partially by the project

CGL2016-76747-R of the Spanish Ministerio de Economía, Industria y

Competitividad and FEDER Funds.

+ Corresponding author: granbaez_29@hotmail.com

(1) https://orcid.org/0000-0003-2049-0409

Received 5 December 2018

Accepted 29 April 2019
The El-Niño South Oscillation (ENSO) is the major climate pattern taking place in the Pacific Ocean showing seesaws between El Niño (warm) and La Niña (cold) episodes, at intervals of two-seven years. This pattern includes both atmospheric and oceanographic variability. The ENSO is related to the southern oscillation index (SOI), an atmospheric oscillation whose periods of negative values, if prolonged over time, coincide with abnormally warm ocean waters across the eastern tropical Pacific, which is typical of El Niño episodes; instead, long positive periods are related to La Niña (i.e. cold water temperatures). SOI is measured as the difference of air pressure between Tahiti and Darwin station. ENSO has been associated with increases in the occurrence of skin diseases, as well as with infectious diseases such as dengue, leishmaniosis and Chagas. ${ }^{(10)}$ On the other hand, SOI has shown positive incidence on malaria in five South African countries, which is positively associated to La Niña and negatively correlated to El Niño.(11)

In the same way, the Antarctic oscillation (AAO), an atmospheric low-frequency variability consisting on a large scale change in atmospheric pressure between the Antarctic region and the southern mid-latitudes, is strongly tele-connected to ENSO during the austral summer season peak. ${ }^{(12)}$ The presence of AAO could explain the highest populations of the long-tail rice rat (Oligoryzomys longicaudatus), which is the main Hantavirus reservoir in southern Chile; ${ }^{(13)}$ but up to now this index has not been directly associated to the development of any disease. 
The Chagas disease was described in 1909 by Carlos Chagas, and is caused by the flagellate protozoan Trypanosoma cruzi. This parasite is transmitted primarily by blood-sucking triatomine vectors. ${ }^{(14)}$ The Chagas disease affects at least 21 countries. In America, it extends from the southern states of the USA to Argentina and Chile, and is considered one of the biggest concerns in public health in Latin America. ${ }^{(14,15,16)}$. Its last outbreak caused 28,000 new cases per year, with an estimated 1516 million people infected and 75-90 million exposed to infection. ${ }^{(17)}$ In Chile, the main vectors involved in the transmission of T. cruzi are arthropods of the Triatominae subfamily (Insecta, Hemiptera, Reduviidae): domestic Triatoma infestans, which is known by the name of "vinchuca" and wild species of the genus Mepraia. ${ }^{(16)}$ Moreover, another main transmission way is through of vectors by fecal-urine way, however, oral way also has been described among others transmission form. ${ }^{(18,19,20,21)}$

The Chagas disease is more common in rural and periurban areas. ${ }^{(16)}$ The report of new cases of Chagas disease has become obligatory in Chile from 1990. Since the year 2000, the interruption of vector transmission of Chagas disease was declared, but the vector is still present, and continues vertical transmission which is coupled to a huge cohort of patients in the indeterminate chronic phase..$^{(20,21)}$

The available data show an average of 2.95 cases per 100 thousand habitants until 2008; for 2009, the number of cases increased until 6.79 reports per 100 thousand habitants, and a new 70\% increase took place in 2011.(22) However, the increase has not been associated to meteorological changes or to higher exposition to the vector. These reports have been associated instead to diagnostictechnique improvements at health centers, as well as to an increase in the proportion of cases in older-age groups (which had remained asymptomatic during 10 to 30 years).

In order to get understand outbreaks of Chagas disease, we search for possible relationships between the frequency of cases in the Chilean population and two atmospheric oscillations in the Southern Hemisphere: SOI and $\mathrm{AAO}$, during the available years with official data.

\section{MATERIALS AND METHODS}

We explored trends in the Chagas disease frequency per year (ChDF) (i.e. number of sick people) in Chile. Because the number of migrant people born outside from Chile increasing significantively between 2014 and 2018 (20) (https://www.abc.es/internacional/ abci-chile-pais-americano-mayor-aumento-inmigrantes-201806190456 noticia.html), which could distort the data (since people born outside of Chile could have been infected with Chagas in distant places), we used for the analysis two different periods from data available official data: (i) 2001 to 2014, (ii) 2001 to 2017. In relation to the monthly annual average of two atmospheric oscillations: AAO, downloaded from the website of the National Weather Service (http://www.cpc.ncep.noaa. gov/products/precip/CWlink/daily_ao_index/aao/aao. shtml), and the SOI, downloaded from the website of the National Oceanic and Atmospheric Administration (http://www.cpc.ncep.noaa.gov/data/indices/soi) (Table).
TABLE

Data used for the study

\begin{tabular}{lccccc}
\hline Year & ChFD & SOI & SOIpy & AAOO & AAOOpy \\
\hline 2001 & 685 & 0.4 & 1.392 & 0.353 & -0.1204 \\
\hline 2002 & 537 & -0.525 & 0.4 & -0.6018 & 0.353 \\
\hline 2003 & 476 & -0.15 & -0.525 & -0.223 & -0.6018 \\
\hline 2004 & 516 & -0.425 & -0.15 & 0.1886 & -0.223 \\
\hline 2005 & 538 & -0.3083 & -0.425 & -0.197 & 0.189 \\
\hline 2006 & 539 & 0.0167 & -0.3083 & 0.257 & -0.197 \\
\hline 2007 & 436 & 0.433 & 0.0167 & -0.468 & 0.257 \\
\hline 2008 & 592 & 1.883 & 0.433 & 0.671 & -0.468 \\
\hline 2009 & 1152 & 0.275 & 1.883 & -0.191 & 0.671 \\
\hline 2010 & 1170 & 1.525 & 0.275 & 0.786 & -0.193 \\
\hline 2011 & 1991 & 2.3083 & 1.525 & -0.0547 & 0.786 \\
\hline 2012 & 1339 & 0.225 & 2.3083 & 0.133 & -0.0547 \\
\hline 2013 & 958 & 0.75 & 0.225 & 0.0317 & 0.133 \\
\hline 2014 & 1018 & -0.22 & 0.75 & 0.08 & 0.03 \\
\hline 2015 & 1264 & -1.33 & -0.22 & 0.71 & 0.08 \\
\hline 2016 & 1370 & -0.19 & -1.33 & 0.57 & 0.71 \\
\hline 2017 & 1507 & 0.36 & -0.19 & 0.45 & 0.57 \\
\hline ChDF & & & & &
\end{tabular}

ChDF: Chagas diseases frequency; SOI: annual average for the monthly South oscillation index; SOIpy: annual average for the monthly South oscillation index previous year; AAOO: annual average for the Antarctic oscillation index; AAOOpy: annual average for the Antarctic oscillation index previous year.

We hypothesised that gaps could be produced between the possible effect of atmospheric oscillation and Chagas disease, as a consequence of a possible cascade of events. For this reason, we included a one-year time lag in the atmospheric oscillations. So, we also used as predictor variables the $\mathrm{SOI}$ and $\mathrm{AAO}$ values recorded one year before [Southern oscillation index in previous year (SOIpy), and Antarctic oscillation in previous year (AAOpy) thereafter] (Table).

Data analysis - In a first step, we analysed the time series for each variable. We searched for temporal autocorrelation and cyclicity in the time series using spectral analysis, to identify periodicity. Time-autocorrelation and spectral analysis was performed with the software PAST (available from website: http://folk.uio.no/ohammer/past/). ${ }^{(23,24)}$

Pearson correlation was used to measure covariations between $\mathrm{ChDF}$ and the annual average of different monthly Southern Pacific atmospheric oscillations (i.e. SOI, SOIpy, AAO, and AAOpy, where "py" denotes values recorded the previous year). The relationship between $\mathrm{ChDF}$ as a dependent variable and the annual average of different monthly Southern Pacific atmospheric oscillations as independent variables was determined by stepwise linear regression. This regression is based on achieving the highest F-value while minimising collinearity of variables in the final model. The normality of the distribution of the variables was tested using the Kolmogorov-Smirnov test for one sample. ${ }^{(25)}$ 
Due to the fact that the official value on number of Chagas patients includes both new cases and chronic cases, the frequency anomaly was used (that is, the observed frequency of one year, minus the average of the period). Thus we obtained values above the average (positive), as below the average (negative). Positive and negative values were transformed into 1 (for positives) and 0 (for negatives). This new binary descriptor was used as the dependent variable to test whether any of the climatic oscillations increased the probability of observing a frequency above the average. This test was performed using forward/backward-stepwise binary logistic regressions.

Model coefficients were evaluated using the omnibus test and Hosmer and Lemeshow test, both follows a Chi-square distribution. ${ }^{(26)}$ Moreover, the discrimination capacity of the model was evaluated with the area under the receiving operating characteristic curve (AUC). The relative importance of each variable within the model was assessed using the Wald test. ${ }^{(26)}$

The relation between the different climatic indices and $\mathrm{ChDF}$ can be also analysed in terms of the accumulated values. ${ }^{(27)}$ Annual values were transformed into anomalies by subtracting the mean value calculated over the whole period 2001-2014. The accumulated values corresponding to specific years were then calculated as the sum of the anomalies of the previous years (e.g. the accumulated values corresponding to 2010 were calculated as the sum of the anomalies for the period 20012014), according to the expression:

$$
\sum_{i=m}^{n} \text { Annual value }_{i} \text { - Mean period }
$$

where $\mathrm{n}$ is the reference year, the annual value of the variable is referred to a particular year (i), and the mean period is the average of the variable values for the whole studied period (i.e. since the initial year $\mathrm{m}=2001$ to the last year $\mathrm{n}=2014$ ).

\section{RESULTS}

Period 2001 to 2014, before the increase in migration - We did not observe temporal autocorrelation or time trend in the study variables. Instead, we detected a significant correlation between $\mathrm{ChDF}$ and $\mathrm{SOI}(\mathrm{r}=0.6$, $\mathrm{p}=0.024, \mathrm{~N}=14)$, SOIpy $(\mathrm{r}=0.704, \mathrm{p}=0.005, \mathrm{~N}=14)$ and AAOOpy $(\mathrm{r}=0.551, \mathrm{p}=0.041, \mathrm{~N}=14)$.

A positive significant relationship between $\mathrm{ChDF}$ and SOIpy was also observed through the following linear equation $\left(\mathrm{F}=11.82, \mathrm{p}=0.005, \mathrm{R}^{\wedge} 2=0.496\right.$, DurbinWatson $=1.284)($ Fig. 1):

$$
\mathrm{ChDF}=657.018+\text { SOIpy } * 350.738
$$

For binary anomalies, we found a statistically significant and positive logistic regression with SOIpy. The model's goodness-of-fit was significant according to the Hosmer and Lemeshow test (Chi-squared $=6.768, \mathrm{df}=$ $8, p=0.562)$, and its discrimination capacity was good $(\mathrm{AUC}=0.854)$. The logit function $(\mathrm{y})$ of the logistic regression was:

$$
\mathrm{Y}=-1.357+1.921 * \text { SOIpy }
$$

In both models, positive SOIpy showed to be an important independent variable to explain the frequency of Chagas disease. The average frequency in 2003, 2004, 2005 and 2006, one year after average monthly SOI showed negative values, was 517; whereas the average frequency in 2007, one year after positive values $(=0.0167)$, was 987 . We observed a similar trend in the analysis of accumulated values (Fig. 2).

Period 2001 to 2017, after the increase in migration - We also observed a significant correlation between ChDF and AAOpy $(r=0.624, p=0.0007, \mathrm{~N}=17)$. A positive significant relationship between ChDF and AAOpy was also observed through the following linear equation:

$$
\mathrm{ChDF}=867,713+\mathrm{AAOpy} * 695.295(\mathrm{~F}=9.573, \mathrm{p}=
$$
$0.007, \mathrm{R}^{\wedge} 2=0.35$ )

\section{DISCUSSION}

On the one hand, Chile implemented a vector control program, which resulted in the elimination of $T$. infestans colonies from domestic spaces, interrupting vectorial transmission to humans in 1999.(28) However, data show increasing incidence of Chagas' disease. ${ }^{(29)}$ Moreover, sylvatic vector populations are present in rural and metropolitan areas, infecting sylvatic and synanthropic mammals species. ${ }^{(30)}$ On the other hand, the number of migrant people born outside from Chile increasing significantively between 2014 and 2018 (https://www.abc. es/internacional/abci-chile-pais-americano-mayor-aumento-inmigrantes-201806190456 noticia.html), ${ }^{(14)}$ for this reason the increasing in the Chagas frequency from these years should be used with caution. Nevertheless, for two different periods analysed here, we observed significant climatic oscillation correlation.

In the current study we found that La Niña phases (related with positive SOI) in previous year could favor the increase of Chagas disease cases. This result could be due to an effect on the enlargement of vector populations involved in the transmission of T. cruzi in Chile. In contrast, $T$. cruzi infections in native rodents from Chile, where a higher prevalence of infection on mammals per unit of area was associated during El Niño events. ${ }^{(31)}$

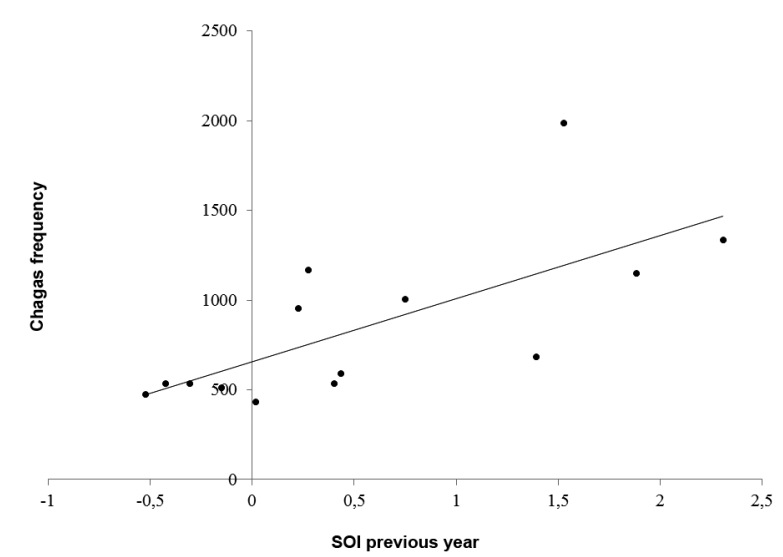

Fig. 1: relationship between South oscillation index (SOI) between Chagas frequency from Chile for the study period. 


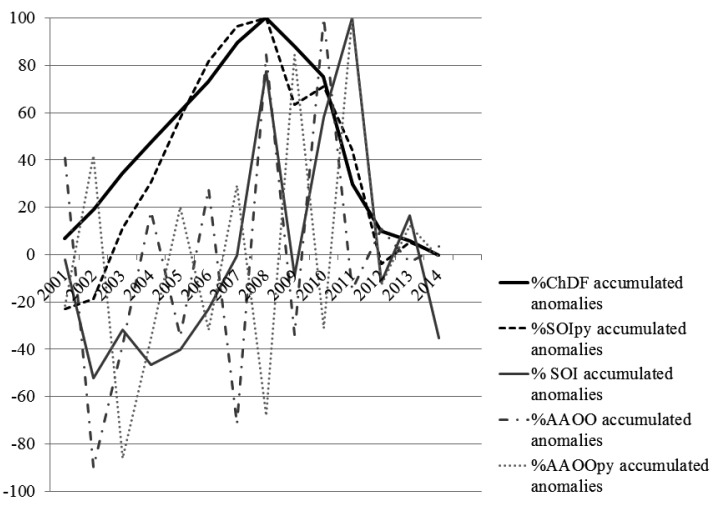

Fig. 2: accumulated anomalies trend in percentages for the studied period (2001-2014), for: Chagas diseases frequency (ChDF), annual average for the monthly South oscillation index previous year (SOIpy), annual average for the monthly South oscillation index (SOI), annual average for the Antarctic oscillation index (AAOO), and annual average for the Antarctic oscillation index previous year (AAOOpy).

This apparent contradiction in the results of both studies could be related. Thus, La Niña phases are continuing with El Niño phases. Therefore, if during La Niña phases with one year of gap favor the increasing to Chagas disease cases, in consecutive years, during El Niño phases, it is possible to observe more cases.

The present results lack of biological explanation for the associations Chagas and atmospheric indices. In this context, present finding, due be considered as first approximation to this issue. Moreover, further studies should provide more evidence in this regard. In this sense, the main weakness of the present study is the short series of data studied.

Menu et al ${ }^{(32)}$ performed a mathematical model suggesting the existence of dynamic interactions between the evolution and epidemiology of Chagas vector as responses to global climatic change. . $^{(32)}$ In addition, it has been proposed that changes in the frequency of Chagas disease in Argentina and Venezuela, specifically in the rural populations, could be highly affected for climatic projections. ${ }^{(33)}$ Climate variability over South America, specifically in Uruguay and Argentina, has shown to influence the development of vectors including those of the Chagas disease. ${ }^{(34)}$ On the other hand, it is expected that climatic change alter El Niño-La Niña pattern. ${ }^{(35)}$ In this context, the present results due be considered, because it is possible observed a increasing of Chagas disease in all South American region.

The ChDF in Chile was found to depend mainly on SOIpy, whose values can be determined one year in advance. Therefore, it is possible to partially forecast annual frequency patterns. This could have important applications in public health strategies and for allocating resources for the management of the disease.

\section{AUTHORS' CONTRIBUTION}

JCB conceived the study; LESA and ICSG provided the data for the study; JCB and JO performed the analysis; JCB, JO, LESA and ICSG drafted the manuscript. All authors read and approved the final manuscript.

\section{REFERENCES}

1. Oreskes N. The scientific consensus on climate change. Science. 2004; 306: 1686.

2. Keller CF. An update to global warming: the balance of evidence and its policy implications. Sci World J. 2007; 7: 381-99. doi: 10.1100/tsw.2007.9.1.

3. Jaykus LA, Woolridge M, Frank JM, Miraglia M, McQuattersGollop A, Tirado C, et al. Climate change: implications for food safety, FAO report. 2007. Available from: ftp://ftp.fao.org/docrep/ fao/010/i0195e/i0195e00.pdf.

4. WHO - World Health Organization. El Niño and health. Protection of the human environment: task force on climate and health. Genova: WHO; 1999. Available from: http://www.who.int/globalchange/publications/en/elnino.pdf.

5. Ebi K. Climate change and health risks: assessing and responding to them through 'Adaptive Management'. Health Aff. 2011; 30(5): 924-30. doi: 10.1377/hlthaff.2011.0071.

6. Baylis M, Barker CM, Caminade C, Joshi BR, Pant GR, Rayamajhi A, et al. Emergence or improved detection of Japanese encephalitis virus in the Himalayan highlands? Trans R Soc Trop Med Hyg. 2016; 110(4): 209-11. doi: 10.1093/trstmh/trw012.

7. Semenza JC, Lindgren E, Balkanyi L, Espinosa L, Almqvist MS, Penttinen $P$, et al. Determinants and drivers of infectious disease threat events in Europe. Emerg Infect Dis. 2016; 22(4): 581-9.

8. Kovats RS. El Niño and human health. Bull World Health Organ. 2000; 78: 1127-35.

9. Redding DW, Tied S, Lo Iacono G, Bett B, Jones KE. Spatial, seasonal and climatic predictive models of Rift Valley fever disease across Africa. Phil Trans R Soc B. 2017; 372: 20160165.

10. Andersen LK, Davis MDP. The effects of the El Niño Southern Oscillation on skin and skin-related diseases: a message from the International Society of Dermatology Climate Change Task Force. Int J Dermatol. 2015; 54(12): 1343-51. doi: 10.1111/ijd.12941.

11. Mabaso ML, Kleinschmidt I, Sharp B, Smith T. El Niño Southern Oscillation (ENSO) and annual malaria incidence in Southern Africa. Trans R Soc Trop Med Hyg. 2007; 101(4): 326-30.

12. Pohl B, Fauchereau N, Reason CJC, Rouault M. Relationships between the Antarctic oscillation, the madden-julian oscillation, and ENSO, and consequences for rainfall analysis. J Clim. 2010; 23: 238-54. doi: 10.1175/2009JCLI2443.1.

13. Murúa R, González LA, Lima M. Population dynamics of rice rats (a Hantavirus reservoir) in southern Chile: feedback structure and non-linear effects of climatic oscillations. Oikos. 2003; 102: $137-45$.

14. Campos-Soto R, Ortiz S, Cordova I, Bruneau N, Botto-Mahan C, Solari A. Interactions between Trypanosoma cruzi the Chagas disease parasite and naturally infected wild mepraia vectors of Chile. Vector Borne Zoonotic Dis. 2016; 16(3): 165-71. doi: $10.1089 / \mathrm{vbz} .2015 .1850$

15. Texeira ARL, Nitz N, Guimaro MC, Gomes C, Santos-Buch CA. Chagas disease. Postgrad Med J. 2006; 82: 788-98. doi: 10.1136/ pgmj.2006.047357.

16. Toso A, Vial F, Galanti N. Transmisión de la enfermedad de Chagas por via oral. Rev Med Chile. 2011; 139: 258-66. doi: 10.4067/ S0034-98872011000200017.

17. Coura JR. Chagas disease: what is known and what is needed - A background article. Mem Inst Oswaldo Cruz. 2007; 102(Suppl. 1): 113-22. Doi: 10.1590/S0074-02762007000900018.

18. Nóbrega AA, García MH, Tatto E, Obara MT, Costa E, Sobel J. Oral transmission of Chagas disease by consumption of acai palm fruit, Brazil. Emerg Infect Dis. 2009; 15(4): 653-5. 
19. Orellana-Halkyer N, Arriaza-Torres B. Enfermedad de Chagas en poblaciones prehistóricas del norte de Chile Chagas disease in prehistoric populations of northern Chile. Rev Chil Hist Nat. 2010; 83: 531-41.

20. Coura JR, Viñas PA, Junqueira ACV. Ecoepidemiology, short history and control of Chagas disease in the endemic countries and the new challenge for non-endemic countries. Mem Inst Oswaldo Cruz. 2014; 109(7): 856-62.

21. Fica A, Salinas M, Jercic MI, Dabanch J, Soto A, Quintanilla S, et al. Enfermedad de Chagas del sistema nervioso central en un paciente con SIDA demostrada por métodos cuantitativos moleculares. Rev Chilena Infectol. 2017; 34(1): 69-76.

22. Ministerio de Salud de Chile. Norma general técnica. Control y prevención nacional de la enfermedad de Chagas. Ministerio de Salud de Chile. 2014. Available from: https://diprece.minsal.cl/ wrdprss_minsal/wp-content/uploads/2016/03/NORMA-TECNICA_CHAGAS_edici\%C3\%B3n-definitiva-140514.pdf.

23. Hammer $\varnothing$, Harper D, Ryan PD. PAST: paleontological statistics software package for education and data analysis. Palaeontologia Electronica. 2001; 4(1): 9.

24. Hammer $\varnothing$, Harper D. Paleontological data analysis. Oxford: Blackwell Publishing; 2006.

25. Zuur AK, Ieno EM, Smith GM. Analysing ecological data. New York: Springer; 2007.

26. Hosmer D, Lemeshow S. Applied logistic regression. 2nd ed. New York: Wiley NY; 2000.

27. Báez JC, Macías D, De Castro M, Gómez-Gesteira M, Gimeno L, Real R. Assessing the response of exploited marine populations in a context of rapid climate change: the case of blackspot seabream from the Strait of Gibraltar. Anim Biodiv Conserv. 2014; 371(1): 35-47.
28. Lorca M, García A, Bahamonde MI, Fritz A, Tassara R. Certificación serológica de la interrupción de la transmisión vectorial de la enfermedad de Chagas en Chile. Rev Med Chil. 2001; 129(3): 264-9.

29. Tapia-Garay V, Figueroa DP, Maldonado A, Frías-Laserre D, Gonzalez CR, Parra A, et al. Assessing the risk zones of Chagas' disease in Chile, in a world marked by global climatic change. Mem Inst Oswaldo Cruz. 2018; 113(1): 24-9.

30. Bacigalupo A, Torres-Pérez F, Segovia V, García A, Correa JP, Moreno L. Sylvatic foci of the Chagas disease vector Triatoma infestans in Chile: description of a new focus and challenges for control programs. Mem Inst Oswaldo Cruz. 2010; 105(5): 633-41.

31. Botto-Mahan C, Campos R, Acuña-Retamar M, Coronado X, Cattan PE, Solar A. Temporal variation of Trypanosoma cruzi infection in native mammals in Chile. Vector Borne Zoonotic Dis. 2010; 10(3): 317-9.

32. Menu F, Ginou M, Rajon E, Lazzari CR, Rabinovich JE. Adaptive developmental delay in Chagas disease vectors: an evolutionary ecology approach. PLoS Negl Trop Dis. 2010; 4(5): e691. doi: 10.1371/journal.pntd.0000691.

33. Medone P, Ceccarelli S, Parham PE, Figuera A, Rabinovich JE. The impact of climate change on the geographical distribution of two vector of Chagas disease: implications for the force of infection. Phil Trans R Soc B. 2015; 370: 1665. doi: 10.1098/ rstb.2013.0560.

34. Tourre YM, Jarlan L, Lacaux JP, Rotela CH, Lafaye M. Spatiotemporal variability of NDVI-precipitation over southernmost South America: possible linkages between climate signals and epidemics. Environ Res Lett. 2008; 3: 044008. doi: 10.1088/17489326/3/4/044008

35. Fasullo JT, Otto-Bliesner BL, Stevenson S. ENSO's changing influence on temperature, precipitation, and wildfire in a warming climate. Geophys Res Lett. 2018; 45(17): 9216-25. 